\title{
EDUCAÇÃO AMBIENTAL E CIDADANIA: EXPERIÊNCIA PROJETO ARQUITETOS DO SABER
}

\author{
Tatiane Almeida Netto, Mirele Milani da Silva, \\ Letícia Fátima de Azevedo, Clayton Hillig
}

\begin{abstract}
Resumo: O projeto "Arquitetos do Saber" é desenvolvido na Escola Rural Dr. Honorato de Souza Santos-Cachoeira do Sul/RS, direcionado a estudantes do ensino fundamental, objetivando a aproximação da educação básica ao ensino superior, a partir de tecnologias sociais, de oficinas ambientais e visitas de estudo. Busca a partir de ações de educação ambiental, cidadania e agroecologia promover o ensino superior e a educação científica na história de vida das crianças integradas ao projeto. As práticas de educação ambiental recorrem ao conceito de simetria discursiva, e através de diálogos prioriza a inserção social do aluno no processo educativo, onde os temas abordados são transversais ao currículo escolar, abordando tópicos em áreas de diversas disciplinas. Estas práticas visam ações que busquem refletir a situação ambiental e social através de diferentes atividades, com o intuito de oferecer e compartilhar com os alunos tarefas educacionais e científicas abordando a sustentabilidade. Fundamentam-se na visão proposta pelo tema transversal meio ambiente e na ação prática, no estímulo à descoberta, ao pensar, ao criar, à experimentação e o debate em sala de aula, buscando a autonomia do aluno através da criticidade a ser desenvolvida, podendo levá-lo a uma racionalidade ambiental.
\end{abstract}

Palavras- chave: inclusão social, educação ambiental, sustentabilidade.

\begin{abstract}
The "Architects of Knowledge" is developed in the Rural School Dr. Honorato de Souza Santos- Cachoeira do Sul /RS, aimed at elementary school students, aiming at the approach of basic education to higher education, from social technologies, workshops environmental and study visits. Search from environmental education, citizenship and agroecology to promote higher education and science education in the life story of children integrated into the project. The environmental education practices refer to the concept of symmetry discursive, and dialogues through prioritizes social inclusion of students in the educational process, where the themes are cross-curricular school, covering topics in the areas of various disciplines. These practices aim at actions that seek to reflect the environmental and social situation through different activities, in order to offer and share with the students educational and scientific tasks addressing sustainability. Based on the view proposed by the environment and cross-cutting theme in practical action, encouraging discovery, thinking, creating, experimentation and debate in class, seeking learner autonomy through criticality to be developed, which can lead it to an environmental rationality.
\end{abstract}

Keywords: social inclusion, environmental education, sustainability. 


\section{Introdução}

Este artigo vem descrever a vivência na ação de extensão do projeto Arquitetos do Saber, desenvolvido na Escola Dr. Honorato de Souza Santos em Cachoeira do Sul/RS, pelos integrantes do Grupo de Pesquisa em Extensão Rural Aplicada do Centro de Ciências Rurais da Universidade Federal de Santa Maria. O "Arquitetos do Saber" é um subprojeto do Projeto Institucional UFSM/CAPES/NOVOS TALENTOS: "Tecnologias para Inclusão Social: Cidadania, Educação Ambiental e Agroecologia", que inclui ainda subprojetos do Centro de Ciências Sociais e Humanas nas áreas de Educomunicação e Arquivologia.

Assim, como a grande maioria das escolas rurais a escola Dr. Honorato de Souza Santos também possui classes multiseriadas, devido ao pequeno número de alunos por série e, embora a escola possua transporte escolar mantido pela Prefeitura Municipal, algumas crianças do entorno (Rincão dos Lopes e Passo dos Ferreira) vão estudar em colégios urbanos. O pequeno número de estudantes e a pouca infraestrutura deixam a escola em situação vulnerável, com constantes ameaças de fechamento em projetos de nucleação e enturmação muito comuns em escolas rurais e peri-urbanas.

O projeto tem como objetivo a aproximação da educação básica ao ensino superior, a partir de tecnologias sociais, com realização de oficinas na escola e na universidade, visando apresentar novas perspectivas, novos conhecimentos científicos e tecnológicos, para, a partir de ações de educação ambiental, cidadania e agroecologia, promover a possibilidade do ensino superior e da educação científica na história de vida dos estudantes do ensino fundamental.

Segundo Silva (2004), nos dias atuais, a educação é vista como uma responsabilidade social dos governantes perante a população, a escola básica é o espaço para aquisição de habilidades, competências e conhecimentos fundamentais ao exercício da cidadania, possibilitando a construção da dignidade humana. A escola é o meio para o desenvolvimento sustentável no campo, através dela podem ocorrer mudanças no paradigma social.

Na localidade do Passo D'Areia, a escola Dr. Honorato de Souza Santos é referencial para o desenvolvimento local, uma vez que a comunidade em torno da mesma encontra-se em situação vulnerável, de risco ambiental e social, por apresentar-se em região periférica e próxima de um lixão. Nesse sentido, o projeto Arquitetos do Saber vem a se desenvolver em parceria com a mesma, pois a escola deve atuar como catalisadora das forças sociais e do poder público, com ações integradas, a fim de promover a cidadania e a valorização da identidade local.

\section{Metodologia}

A metodologia utilizada para o desenvolver desse projeto foi à pesquisa-ação, apoiada pela instituição, inserido no Projeto Institucional UFSM/Tecnologias de Inclusão social: cidadania, educação ambiental e agroecologia. Financiado pelo Edital CAPES n0.033/Novos Talentos 2010.

O projeto visa mudanças no comportamento da comunidade escolar atendida, sendo que as ações são fundamentadas na epistemologia da educação ambiental, agroecologia e educação popular. As atividades desenvolvidas no projeto Arquitetos do Saber foram articuladas em: práticas de educação ambiental, agroecologia e cidadania, divididas em: saídas de estudo, construção da horta agroecológica, oficinas, seminários e campanhas ambientais. 
As atividades ocorrem em horário alternativo a jornada escolar, nos meses de março a dezembro de 2011, com 25 alunos, na faixa etária de 06 a 12 anos, da Escola Estadual de Ensino Fundamental Dr. Honorato de Souza Santos, localizada no município de Cachoeira do Sul/RS, na localidade Passo d' Areia. A localidade de Passo D'Areia insere-se na área periurbana de Cachoeira do Sul, onde se localiza a comunidade do Rincão dos Lopes e Passos dos Ferreira. Os moradores do Rincão dos Lopes ocupam-se, basicamente, da extração de madeira e catação de lixo reciclável no Lixão Municipal, sendo que este se situa a dois quilômetros dessa localidade. A localidade de Passos do Ferreira caracteriza-se como uma comunidade rural, que desenvolve atividades agrícolas e não-agrícolas.

Os métodos utilizados no desenvolvimento das atividades: educação ambiental, cidadania e agroecologia, foram coerentes ao conceito de simetria discursiva, desenvolvido por Paulo Freire e pela Teoria da Ação Comunicativa desenvolvida por Habermas, onde as atividades ocorrem através de diálogos, interações entre os estudantes, conhecimento partilhado com o aluno e não somente direcionado a ele. Desta forma, prioriza a inserção do aluno no processo educativo, promovendo a inserção social contextualizada com o tema de educação ambiental e a transversalidade ao currículo escolar, abordando tópicos em áreas das disciplinas de geografia, ciências, história e matemática.

O processo-ensino-aprendizagem é visto como ato de conhecimento e transformação social, sendo pautada na perspectiva política, e possui como principal característica a utilização do saber da comunidade como matéria prima para o ensino, focando a aprendizagem a partir do conhecimento do sujeito e ensinando a partir de palavras e temas geradores do cotidiano dele.

As práticas de cidadania (Fig. 01) incluem oficinas de fotografia, para exercícios e vivências identitárias e ambientais; seminários temáticos para esclarecimentos dos direitos e fundamentos do Estado Democrático, enquanto vivência cotidiana; visitas aos setores de assistência estudantil e jurídica na universidade, além de apresentação de setores do Estado, como a Casa da Cidadania, a Câmara de Vereadores e a Polícia (qual?). A cidadania, dessa forma tem um caráter de formação política, além de demonstrar aos alunos as diversas formas de acesso a direitos como educação, inclusive em nível superior, saúde, segurança, lazer e sustentabilidade ambiental.

As práticas de educação ambiental (Fig. 02 e 03), fundamentam-se na visão proposta pelo tema transversal meio ambiente e na ação prática, no estímulo à descoberta, ao pensar, ao criar, à experimentação e ao debate em sala de aula. Visa desenvolver a capacidade de observação e pesquisa do aluno, estimular seu senso crítico em relação às questões ambientais, despertar a reflexão sobre a importância da preservação do meio ambiente e do respeito à natureza e incentivar no aluno a participação e o trabalho na busca de soluções para a melhoria da qualidade de vida de todos.

Nas práticas de agroecologia, foram utilizadas técnicas de produção agroecológicas, integrando assim os alunos a práticas que visem à preservação ambiental tais como: criação de uma horta (Fig. 04) que será mantida com adubação orgânica (a adubação orgânica é feita através da utilização de vários tipos de resíduos, tais como: esterco curtido, vermicomposto de minhocas, compostos fermentados) e adubação verde (cultivo de plantas que estruturam o solo e o enriquecem com micronutrientes e macronutrientes). 


\section{Monografias Ambientais IsSN: 2236-130}

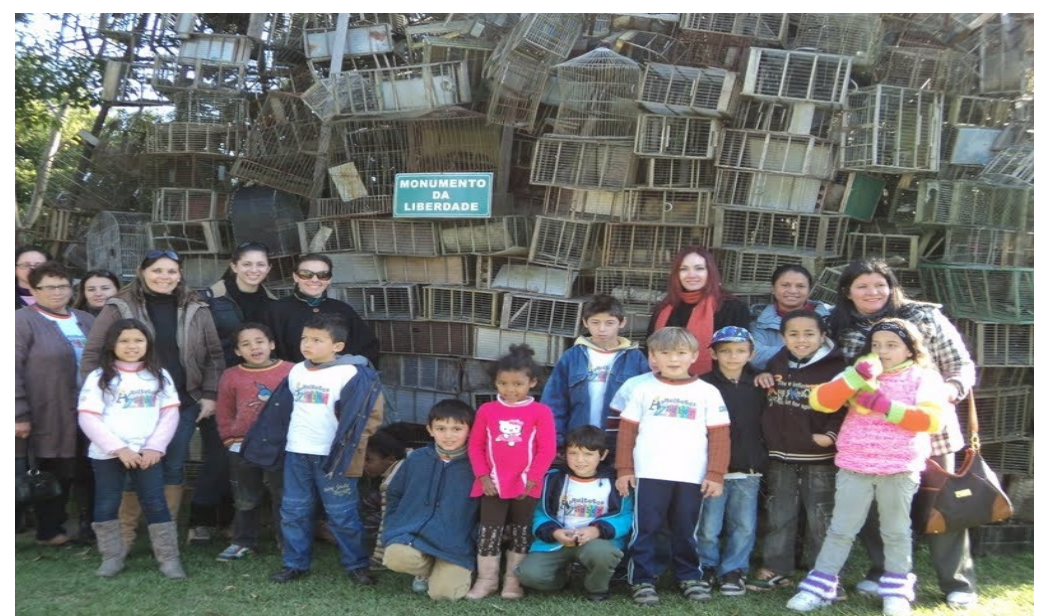

Figura 01- Visita ao Criadouro Conservacionista São Braz/Santa Maria-RS Crédito: 3autor (2011)

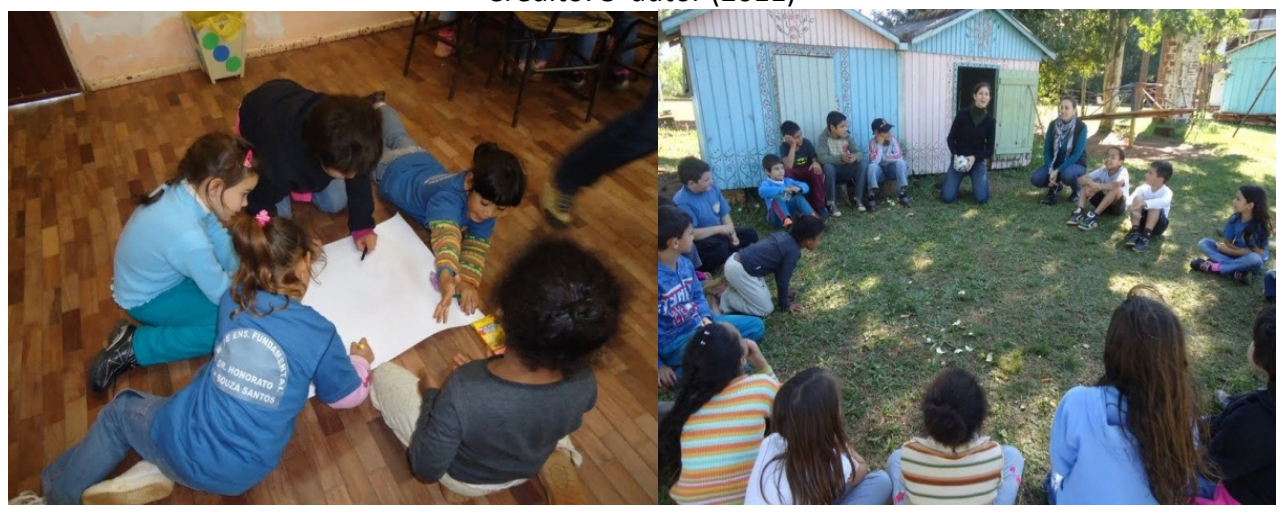

Figura 02 e 03- Atividades educação ambiental Crédito: 3o autor (2011)

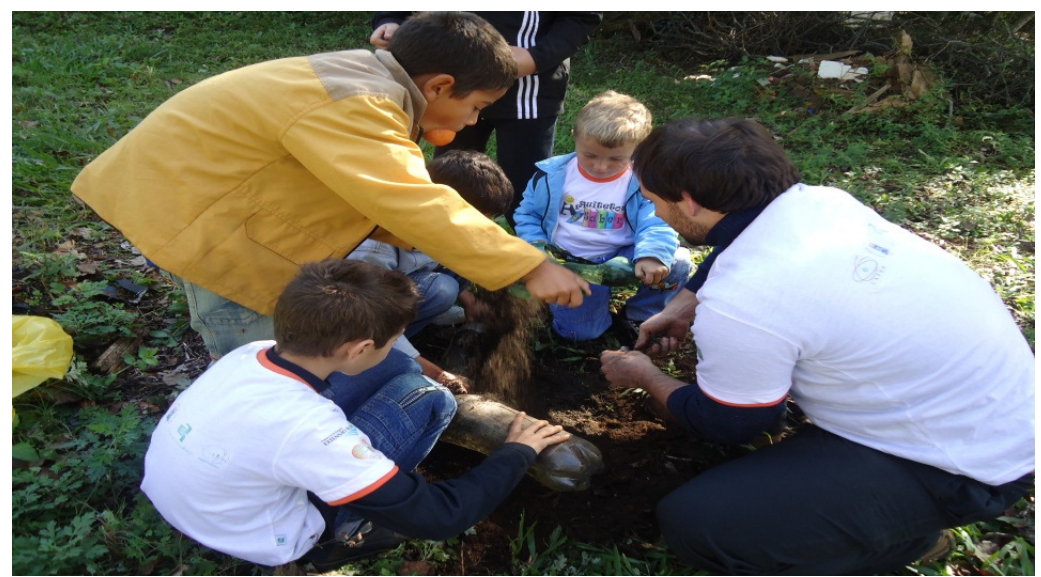

Figura 04- Atividade junto à horta agroecológica Crédito: 2ㅇ autor (2011) 


\section{NETTO et al., vol.(5), n5, p. $992-999,2012$.

REMOA

\section{Resultados e discussão}

O campo é formado por diferentes territórios, que exigem políticas econômicas e sociais diversas, na localidade em torno da escola, vivencia-se uma comunidade em vulnerabilidade social e ambiental onde é preciso trabalhar a autonomia crítica com as crianças, podendo atingir as famílias no desenvolvimento do projeto, para através de uma construção de valores desenvolverem a transformação social e a emancipação humana rumo ao desenvolvimento.

A população do campo tem o direito de pensar o mundo a partir do lugar em que vive, a partir da sua realidade, momento em que o sujeito do campo pensa o mundo através da realidade da cidade, do meio urbano, leva ao estranhamento de si mesmo, o que dificulta a construção da identidade, condição fundamental da formação cultural e da cidadania (FERNANDES, 2002).

Nesse sentido, procurou-se no desenvolver desse projeto a realização de práticas integradas e integradoras com o objetivo real de emancipar os sujeitos para a construção de sua trajetória com mais liberdade, diversidade, equidade e sustentabilidade. A integração entre os temas: cidadania, agroecologia e educação ambiental são tão fortes, que no próprio desenvolvimento do projeto fica difícil distinguir uma prática da outra.

Atualmente a educação do campo encontra-se fragmentada em seu processo curricular, desvinculada de um contexto histórico e distanciada da realidade na qual o sujeito vive, ao educando é repassado um pensamento unidimensional, sem destacar e fazer perceber a visão geral, e é nesse sentido que se busca a complexidade ambiental, para uma nova compreensão do mundo, que incorpore o limite do conhecimento e da incompletude do ser, onde se constrói e se aprende através do processo dialógico de saberes, na hibridação da ciência, das tecnologias e dos saberes populares (LEFF, 2003).

A complexidade ambiental necessita de uma pedagogia do ambiente e de um ambiente da pedagogia para engajar-se com a vida do campo e, assim, comprometer-se com a igualdade e justiça social e com valores como a solidariedade, estes capazes de selarem um novo contrato solidário entre os sujeitos sociais e a natureza. Identifica-se carência de uma ciência apta para confrontar as questões da sustentabilidade, para afrontar os problemas da complexidade é necessário um enfoque distinto da disciplina científica tradicional, capaz de integrar uma pluralidade de conhecimentos e perspectivas (FUNTOWICZ E MARCHI, 2000).

Para Pinsky e Pinsky (2003), a cidadania é uma condição social resultante da individualização e do contrato social modernos. A cidadania é um papel social real que propicia prerrogativas, as relações entre provimentos e prerrogativas estão na base do conflito social moderno. Os direitos e obrigações da cidadania são, em qualquer condição, não apenas públicos, mas universais. Dessa forma, a cidadania constitui-se em uma construção social específica, o autor alerta que a cidadania é resultado da trajetória de uma sociedade e depende da ética e valores sobre os quais está estabelecida.

Sendo assim, torna-se necessária a compreensão de que a igualdade, em direitos civis, sociais e políticos, carecem de medidas que promovam não só direitos iguais, mas oportunidades semelhantes para todos, guardando o princípio da universalidade e da democracia para a busca da equidade social. Deste modo, a cidadania deve levar em conta não somente a questão da igualdade de direitos e da liberdade civil, propostas pelos precursores iluministas, como Locke e Rosseau, mas pensar a cidadania a partir da diversidade e equidade sociais.

Ao utilizarmos da epistemologia da educação popular, buscamos o resgate da cidadania e a necessidade da inclusão em todos os sentidos. Paulo Freire em suas obras, "A Educação como 
Prática de Liberdade" e "Pedagogia do Oprimido", externa seu entendimento de popular como sinônimo de oprimido. Segundo ele, a educação pode se tornar um agente importante nos processos de libertação do indivíduo e da sociedade. Uma educação que arraste consigo procedimentos que incentivem a participação, ou seja, um meio de veiculação e promoção para a busca da cidadania, compreendida em suas dimensões crítica e ativa. Uma educação que contribua ao exercício de cobranças das ações políticas geradas em nome do povo e que também possa incentivar aspectos éticos e utópicos que, para os dias de hoje, se tornam uma exigência social.

Tornar popular a educação compreende sua universalização e democratização em diferentes níveis tornando-a de fato acessível às camadas populares pela via do conhecimento e da cidadania, frente às condições necessárias a transformação social e a emancipação humana, finalidade da ação político-pedagógica. É uma estratégia de construção da participação popular para o redirecionamento da vida social.

A educação popular é uma educação comprometida e participativa, orientada pela perspectiva de realização de todos os direitos do povo, o processo-ensino-aprendizagem é visto como ato de conhecimento e transformação social, sendo pautada na perspectiva política, sua principal característica é utilizar o saber da comunidade como matéria prima para o ensino, aprender a partir do conhecimento do sujeito e ensinar a partir de palavras e temas geradores do cotidiano dele.

Nesse projeto, a educação ambiental foi abordada junto à escola regular procurando trazer a vivência dos alunos do meio rural, a integração com a natureza, nas práticas e oficinas e nas atividades e trabalhos em grupo. Já a epistemologia da educação popular foi utilizada por compreender o processo educativo num sentido mais amplo, onde se entende que a transformação das relações dos grupos humanos com o meio ambiente está inserida dentro do contexto da transformação da sociedade. A educação popular pode ser um processo de mediação educativa alicerçada ao espírito agroecológico.

Através dos diálogos e da ação comunicativa oriunda das atividades busca-se através da convivência entre sujeitos, uma nova formulação de valores, para a comunidade escolar, valores que devem ser baseados na solidariedade e na fraternidade, devendo adotar-se uma política pela vida. Com o desenvolver das ações de educação ambiental, agroecologia e cidadania podemos plantar a semente da cooperação que está presente em todo processo social no momento em que utilizamos do diálogo e o respeito às diferenças, buscamos a autonomia do aluno através da criticidade desenvolvida podendo levá-lo a uma racionalidade produtiva/ambiental.

Ao adotarmos a perspectiva de racionalidade ambiental nos referimos a Leff o qual define que a racionalidade ambiental consiste em respeitar a biodiversidade, praticar a vontade ontológica do ser e a troca de conhecimentos para aprender mais e viver melhor (BARBOSA, 2010).

Entende-se que a transformação das relações dos grupos humanos com o meio ambiente está inserida dentro do contexto da transformação da sociedade. A educação popular pode ser um processo de mediação educativa alicerçada ao espírito agroecológico. Neste sentido, este trabalho compreende a importância de trabalhar com crianças e jovens rurais, pois se entende como fundamental prepará-los para permanecer na agricultura familiar de forma pluriativa, apropriando-se de conhecimentos que favoreçam desenvolver atividades mais sustentáveis e que superem os atuais impasses econômicos, sociais e ambientais.

O projeto adotou a tecnologia social como abordagem, compreendendo produtos e técnicas reaplicáveis, desenvolvidas na interação com a comunidade e que representem efetivas 
soluções de transformação que, necessariamente, inclui mudanças em todos os âmbitos da vida, incluindo a relação entre os seres humanos e destes com a natureza. Conforme a Rede de Tecnologia Social (RTS) adota-se como conceito de Tecnologia social: “...técnicas e metodologias transformadoras, desenvolvidas na interação com a população, que representam soluções para a inclusão social" (BAVA, 2004 , p.106). A tecnologia social deve ser potencializada na perspectiva de se ampliar a compreensão dos referenciais sobre desenvolvimento e inclusão social, e de se construir alternativas que possibilitem a difusão e reaplicação, de forma democrática e participativa, de tecnologias sociais, na perspectiva da co-gestão, da produção de conhecimentos, da solidariedade, do aprofundamento da consciência comunitária ampliando o conceito de inclusão social e de sustentabilidade.

\section{Conclusões}

Ao integrarmos a educação ambiental e educação popular no desenvolvimento desse projeto visualizamos a integração dos aspectos sociais, ecológicos e culturais de uma educação do campo. A educação ambiental alicerçada à educação popular num processo de transição para uma sociedade sustentável que apoia e constrói a cidadania. Para construirmos a prática da cidadania é necessário mudarmos os valores éticos e culturais, assumir compromissos com a soberania, solidariedade, sustentabilidade, democracia e segurança alimentar.

A transformação social implica em co-participação de diferentes sujeitos sociais envolvidos no processo, atuando como protagonistas em um propósito de (re) construção social. Vista desta forma, a participação deve ser concebida como um ato interativo, na perspectiva de conhecer o contexto no qual encontram-se inseridos, as situações que precisam de intervenção e as alternativas para superação, utilizando para esta finalidade a mediação e o ato comunicativo. Trata-se, portanto de um processo de reflexão-ação, característico dos processos de comunicação marcados pela participação ativa dos sujeitos envolvidos e pela valorização do saber local que se inter-relaciona ao saber científico.

O projeto proporcionou as crianças uma nova vivência, uma transformação não só em saberes, mas perspectivas de novos horizontes, a utilização de práticas como educação ambiental, cidadania e agroecologia alicerçadas na educação popular, permite a troca de saberes, o diálogo, e também a aproximação ao ensino superior, à construção crítica da realidade no contexto social e ambiental. Permitindo assim, a apropriação de conhecimentos científicos e tecnológicos aproximando os mundos da educação básica e do ensino superior. 
REMOA

\section{Monografias Ambientais issn: 2236-130}

\section{Referências bibliográficas}

BARBOSA, E. B. Economia e Racionalidade ambiental. $2010 . \quad$ Disponível em: <http://www.administradores.com.br/informe-se/artigos/economia-e-racionalidade ambiental/45992/>. Acesso em: 09 jun.2011.

BAVA, S. C. Tecnologia social e desenvolvimento local. In: Tecnologia social: uma estratégia para o desenvolvimento. Fundação Banco do Brasil - Rio de Janeiro, 2004.

FERNANDES, M. F. Diretrizes de uma caminhada. In: Edgar, J. K.; Paulo, R. C.; Roseli, S C. (Orgs). Educação do campo: Identidade e políticas públicas. Brasília, DF: Articulação nacional por uma educação do campo, 2002, p. 89-103.

FREIRE, P. Pedagogia do oprimido. Rio de Janeiro: Paz e Terra, 1988, 18a edição.

Pedagogia da autonomia. Saberes necessários à prática educativa. 3. ed. Rio de

Janeiro: Paz e Terra, 1997.

FUNTOWICZ S.; MARCHI, B. de, Ciencia Posnormal, Complejidad Reflexiva y Sustentabilidad. In: LEFF, E. (ed.). La Complejidad Ambiental, Siglo XXI, Mexico, 2000.

LEFF, H. La complejidad ambiental Mexico: Siglo XXI, 2 ed., 2003.

PINSKY, J.; PINSKY, C. B. orgs. História da cidadania. São Paulo: Contexto, 2003.

SILVA, M. do S. Educação do Campo e Desenvolvimento: uma relação construída ao longo da história. 2004. Disponível em:< http://www.contag.org.br/imagens/f299Educacao_do_Campo_e_Desenvolvimento_Sustentavel.pdf> Acesso em: 10 jun.2011. 